\title{
Limiting life-prolonging interventions and providing palliative care towards the end-of-life in Indian inten- sive care units*
}

\author{
R. K. Mani, P. Amin, R. Chawla, J. V. Divatia, F. Kapadia, P. Khilnani, S. N. Myatra, S. Prayag, R. \\ Rajagopalan, S. K. Todi, R. Uttam, S. Balakrishnan, A. Dalmia, A. Kuthiala
}

Purpose: This position statement aims to minimize inappropriate treatment and optimize palliative care for terminally ill patients in Indian intensive care units by standardizing the process of forgoing life support. It also defines the ethical standards for the physician-patient relationship in the context of critical care practice in India.

Evidence: Evidence was gathered through a review of recently published medical literature on the subject, as well as by evaluating the relevant statutes of Indian Law. Available empirical data from critical care practice in India were sparse. Newspaper articles reflecting lay opinion on related issues were also reviewed. The terms for search were: end-of-life care; withdrawal and withholding; intensive care; terminal care; medical futility; ethical issues; palliative care.

Method: Proposals from the Chair were debated and recommendations were formulated through a consensus process. The process took into account the guiding ethical principles and clinical practices elsewhere in the world, and incorporated the socio-cultural and legal perspectives unique to this country.

\section{Recommendations}

1. The physician has a duty to disclose to the capable

From:

Committee for the Development of Guidelines for limiting life-prolonging interventions and providing palliative care towards the end of life: Indian Society of Critical Care Medicine patient or family, the patient's poor prognosis with honesty and clarity when further aggressive support appears nonbeneficial. The physician should initiate discussions on the treatment options available including the option of no specific treatment.

2. When the fully informed capable patient or family desires to consider palliative care, the physician should offer the available modalities of limiting lifeprolonging interventions.

3. The physician must discuss the implications of forgoing aggressive interventions through formal conferences with the capable patient or family, and work towards a shared decision-making process. Thus, he accepts patient's autonomy in making an informed choice of therapy, while fulfilling his/her obligation to provide beneficent care.

4. Pending consensus decisions or in the event of conflicts between the physician's recommendations and the family's wishes, all existing supportive interventions should continue. The physician however, is not morally obliged to institute new therapies against his/ her better clinical judgment.

5. The discussions leading up to the decision to withhold life-sustaining therapies should be clearly documented in the case records, to ensure transparency and to avoid future misunderstandings. Such documentation should mention the persons who participated in the decision-making process and the treatments withheld or withdrawn.

6. The overall responsibility for the decision rests with the attending physician/intensivist of the patient, who 
must ensure that all members of the caregiver team including the medical and nursing staff agree with and follow the same approach to the care of the patient.

7. If the capable patient or family consistently desires that life support be withdrawn, in situations in which the physician considers aggressive treatment nonbeneficial, the treating team is ethically bound to consider withdrawal within the limits of existing laws.

8. In the event of withdrawal or withholding of support, it is the physician's obligation to provide compassionate and effective palliative care to the patient as well as attend to the emotional needs of the family.

'Dying can be a peaceful event or a great agony when it is inappropriately sustained by life support' Roger Bone ${ }^{[1]}$

In the context of critical care, the physician's approach to the patient has three dimensions: medical, ethical, and legal. This is because critical care involves the application of life-supporting interventions.

Death is an everyday occurrence in the critical care unit. The dying frequently do so in critical care units: it is estimated that one in five Americans die using intensive care. ${ }^{[2]}$ For many, life-support interventions have not helped to mitigate their suffering, but have rather added the agony and burden of a prolonged dying process. Death, which we all wish to be peaceful and to occur in the presence of loved ones, has become artificial, away from the family surrounded by the paraphernalia of modern critical care. Prolonged and futile life support has undoubtedly imposed enormous economic strain on patients and families. Potentially salvageable patients can be denied ICU care when scarce beds and resources are consumed in a futile search of cure where death appears inevitable.

\section{Where critical care is unlikely to save a patient's life or to restore him to a meaningful existence, what is the responsibility of the physician?}

In today's world limitation of life-supporting interventions is being increasingly practiced, as physicians realize that the mission of intensive care includes the avoidance of inappropriate use of aggressive interventions. ${ }^{[3]}$ In the US and in Europe, withholding or withdrawal preceded death in up to $90 \%$ of dying patients in critical care units ${ }^{[4]-[6]}$ and $10 \%$ of admissions. ${ }^{[6]}$ The proportion of patients dying with a decision to limit life support increased from 51 to $90 \%$ over the 5-year period from $1988^{[7]}$ to $1992 .^{[8]}$ In Pediatric ICUs, retrospective studies in the last decade suggest that $40-60 \%$ of all deaths follow an end-of-life (EOL) decision. ${ }^{[9]}$ In contrast, in Indian ICUs withholding and withdrawal of life-supporting interventions (WOLS) preceded deaths in only $22 \%$ in one center in New Delhi ${ }^{[10]}$ and in 19, 40, and 50\%, respectively in three centers in Mumbai. ${ }^{[11]}$ In the vast majority, however, the prevailing practice appears to be full, and often heroic, support until the very end, although precise empirical data on these practices is yet to be generated.

The customary practices in India, however, may not accurately reflect the changing physician attitudes. In response to a questionnaire among 169 intensive care physicians in a recent survey $80 \%$ felt there is a need for forgoing life-supporting interventions in critical care and $55 \%$ practice 'do not resuscitate' (DNR) directives discreetly and unilaterally (R. K. Mani, personal communication). The majority appeared to have fears of possible misuse of the life-support limiting approach or of being misunderstood by the families of patients.

There are several impediments to change in EOL practices in India: the approach of the physician is generally 'paternalistic,' as the concept of patient autonomy is weak in the prevailing cultural ethos. The physician's orientation by his training is only to a curative approach to disease rather than to one of palliation even when the patient's prognosis is poor. The physician is generally fearful of being accused of providing sub optimal care or of possible civil or criminal liability of limiting therapies. Adding to his dilemma, there is a virtual absence of ethical or legal guidelines for treating patients in intensive care units. Self-determination of patients relating to medical decisions is not well articulated in our Constitution. ${ }^{[10]}$ Indeed the position of the law with respect to death in dignity is unclear, as Indian courts have only addressed appeals for Euthanasia. ${ }^{[12-14]}$ In the US and in Europe, the Laws have evolved over the last three decades to accommodate the changing paradigm, ${ }^{[15-17]}$ while in India debate on the issue has only just begun. ${ }^{[18-20]}$

The need for this change, however, is of vital importance to India for several reasons. There is an unbear- 
able financial burden to the average patient as healthcare expenses are borne mostly by the individual. ${ }^{[11]}$ Lack of appropriate policies for limiting life support make fair distribution of scarce facilities impossible in this populous country. Moreover, a technologically prolonged dying process takes away the serenity and dignity accorded to it by the established cultural traditions and beliefs.

\section{Ethical principles}

Among the four cardinal ethical principles upon which the practice of critical care is grounded, respect for patient's autonomy has come to take precedence over the other three namely - beneficence, nonmaleficence, and distributive justice. ${ }^{[3,5,15,16,21,22]}$

Autonomy means the right to self-determination, where the informed patient has a right to choose the manner of his treatment. To be autonomous the patient should be competent to make decisions and choices. In the event that he is incompetent to make choices, his wishes expressed in advance in the form of a Will, or the wishes of surrogates acting on his behalf ('substituted judgment') ${ }^{[3]}$ are to be respected.

Beneficence is acting in what is (or judged to be) in patient's interest. In critical care, increasingly the physician is expected to care for patients with a high risk of death. The principle of beneficence requires that the physician act in the best interests of the patient and his family, and therefore, his responsibility should extend beyond medical treatment to ensuring compassionate care during the dying process. In this context, the physician's expanded goals include facilitating (neither hastening nor delaying) the natural dying process, avoiding, or reducing the sufferings of the patient and his family, providing emotional support and protecting the family from financial ruin. This is not to be confused with euthanasia, which involves the physician's deliberate and intentional act through administering a lethal injection or by other means to end the life of the patient. When the physician, acting unilaterally, makes decisions for the patient, he is said to be 'paternalistic. [15,16] Respect for patient's autonomy requires that beneficence also consist of educating the patient to enable him/her to make an informed choice.

Nonmaleficence means doing no harm and avoiding the imposition of unnecessary or unacceptable burdens on the patient. This is subject to varied interpretation, as the same act may be construed as harmful or beneficial depending on the circumstances. ${ }^{[21]}$ In practical terms, it requires the physician not to act contrary to the patient's values and perspectives.

Distributive justice means that patients in similar circumstances should receive similar care. Physicians need to have a socially responsible behavior, which makes it their duty to make good use of the material, financial, and human resources under their control. The physician may thus provide treatment and resources to one with a potentially curable condition over another for whom treatment will be futile. ${ }^{[21]}$

\section{When to initiate EOL discussions}

A workable instrument of mortality prediction is necessary to identify situations where EOL discussions can begin. Whether a patient is going through the dying process or not is not always clear. Often the clinician's judgment is colored by his own biases and attitudes towards death. ${ }^{[24-26]}$

As with any diagnostic process identifying these situations needs expertise and experience. Each of the following criteria is not to be used in isolation, but in the context of the entire clinical history and status of the patient. When faced with prognostic uncertainty the physician should not take precipitous decisions but wait for the disease process to unfold.

The following list is not to be regarded as definition of medical futility, but should be used as an aid to recognize when to start discussions on EOL issues.

\section{Checklist for initiating EOL discussions}

1. Advanced age coupled with a poor premorbid state due to chronic debilitating diseases, e.g., advanced chronic obstructive pulmonary disease (COPD) requiring home oxygen and/or bilevel pressure support or with severe impairment of quality of life; advanced interstitial lung disease on oxygen therapy with failed medical treatment, chronic renal failure requiring long-term dialysis, chronic liver disease, advanced congestive heart failure.

2. Catastrophic illnesses with organ dysfunctions unresponsive to a reasonable period of aggressive treatment. 
3. Prolonged coma (in the absence of brain death) due to acute nonreversible causes or chronic vegetative state.

4. Incurable chronic severe neurological states rendering meaningful life unlikely, e.g., progressive dementia, quadriplegia with ventilator dependency.

5. Progressive metastatic cancer where treatment has failed or patient refuses treatment.

6. Postcardio respiratory arrest nonrestoration of comprehension after a few days.

7. Comparable clinical situations coupled with a physician prediction of low probability of survival.

8. Patient/family preference to limit life support or refusal to accept life support.

\section{Rationale}

Absolute certainty in the anticipation of death is impossible. However, mortality prediction is central to communication and decisions in the critical care setting. A variety of scoring systems have been developed based on physiological variables, however, none is reliable enough to be adequate for individual patients. ${ }^{[23,27]}$

Despite these difficulties empirical data has accumulated that can guide the physician's predictive judgment. Indirect evidence for the validity of the 'checklist' is found in the form of epidemiological data on ICU mortality and ICU use by decedents, ${ }^{[2]}$ prospective and retrospective observational studies on WOLS ${ }^{[5,6,27,28]}$ and from predictive tools that have been used in prospective studies on DNR directives and WOLS in both emergency room and ICU setting. ${ }^{[31,33]}$ These data help to identify the patient characteristics that physicians generally use for limiting aggressive therapy.

In Angus et al's ${ }^{[2]}$ report of US epidemiological data, while most of the deaths among infants occurred in the ICUs of hospitals, elderly patients were far less likely to be hospitalized or admitted to the ICU at the time of death. Only $14 \%$ of the very elderly (beyond 85 years) were in the hospital or ICU at the time of their demise. ICU use was found to be limited for metastatic cancer as compared to acute myocardial infarction. These data suggest that advanced age and certain disease conditions lead the physicians to limit or the patients to avoid ICU admission and aggressive treatments.

According to a multicenter, prospective, observational study in Europe, decisions for treatment limitation were related to age and diagnosis among others. ${ }^{[6]}$ Age, poor prognosis, and poor predicted quality of life were among the reasons cited in studies from France ${ }^{[5]}$ and Canada. ${ }^{[28]}$ In the latter series, the mean age of patients undergoing withdrawal of support was $65 \pm 14.6$ with most individuals having severe dysfunction of at least one organ system. They also found that the timing of WOLS decisions from ICU admission depends on the type and severity of the disease. The probability of life-support limitation and intensive care mortality is high when the subjective estimate of the physician for intensive care survival is $<10 \%$. ${ }^{[27,29,30]}$ These data again give us insight into the considerations of physicians while initiating palliative care.

Evidence from DNR directives or ICU admission policies also helps to define how physicians may anticipate death with a view to initiating EOL discussions. Sinuff et al. ${ }^{[31]}$ found that physician prediction of low probability of survival, physician perception of patient preference to limit life support, medical rather than surgical diagnosis and age are the strongest independent determinants of DNR directives. An earlier study ${ }^{[32]}$ did not find age or severity of illness as independent predictors for WOLS decisions, as such decisions, requiring physician-family consensus, are far more complex than setting DNR directives. Similarly, Le Conte et al. ${ }^{[33]}$ reported the determinants of DNR directives to be advanced age (mean age $75 \pm 13$ years), chronic cardiopulmonary disease, metastatic cancer or patients with acute nontreatable illness. In a recent study, ${ }^{[34]}$ nurses perceived that the conduct of EOL care in the ICU was improved by the use of DNR and WOLS checklists.

In the ETHICUS ${ }^{[6]}$ study, the greatest frequency of limitations occurred for acute neurological diseases.

In acute illness, response to therapy may sometimes be surprisingly better than anticipated and observation over time or serial scoring coupled with physician prediction may improve prognostication. ${ }^{[30]}$ It should be noted that 'cut off' values for age or duration of observation before considering EOL care are hard to determine as they vary with the overall health status of the patient and the nature of his disease.

Absolute objectivity in mortality prediction has so far 
been elusive. As a result, definitions of futility (such as the American Thoracic Society's: 'a life-sustaining intervention is futile if reasoning and experience indicate that the intervention would be highly unlikely to result in a meaningful survival for that patient ${ }^{[35]}$ are often only suggestive rather than definitive.

\section{For pediatric patients}

Worldwide, pediatricians are becoming more proactive in managing death and the dying. ${ }^{[36]}$ The EAC-RCPCH guidelines ${ }^{[37]}$ cite the following situations as justification for limitation and withdrawal of interventions:

- The permanent vegetative state.

- The 'no chance' situation where there is expectation of imminent death despite aggressive treatment.

- The 'no purpose' situation where there is decrease in quality of life despite potentially extended survival.

- The 'unbearable' situation where in the face of progressive illness further treatment is more than can be borne.

\section{Recommendations for limiting life-support interventions}

\section{Recommendation 1}

The physician has a duty to disclose to the capable patient or family, the patient's poor prognosis with honesty and clarity when further aggressive support appears nonbeneficial. The physician should initiate discussions on the treatment options available including the option of no specific treatment.

Rationale: Respect for patient's autonomy and the imperative to act in his best interest are the basis for providing accurate information, as we move away from the 'paternalistic' model of care worldwide. ${ }^{[6,15,22,23,35,38]}$ It is important for the physician to identify a suitable family member as a surrogate decision-maker for the patient, as less than $5 \%$ of patients are able to communicate with the physician regarding issues relating to life support. ${ }^{[7,8,23]}$ The 'family' means spouse, children, parents, siblings, and the next of kin who is available or even a trusted friend, though a hierarchy of surrogates does not exist in Indian law for making EOL decisions. Advance Directives stating the patient's preference is not a practice in India but public awareness in this regard should be encouraged.
Curative and palliative measures are coexistent but varying in degree at different phases of critical illness. ${ }^{[17,38]}$ Therefore, the physician must initiate discussions early and clearly state the patient's condition. Waiting, watching, and postponing discussions on prognosis may be more stressful to the family as well as the ICU staff[39] than to face bad news squarely.

Practice points: It is important that the physician gives as accurate a prognosis as is possible, clarifying that uncertainty is inherent in the treatment of critical illness, in language and in terms that the family can understand. a. It is the responsibility of the physician to inform the capable patient or his family the diagnosis, prognosis, the range of appropriate therapeutic interventions available as well as the option of no specific therapy, including their risks, benefits, costs, and consequences. ${ }^{[35]}$

\section{Recommendation 2}

When the fully informed capable patient or family desires to consider palliative care, the physician should offer the available modalities of limiting life-prolonging interventions.

The patient or family should be clearly made aware of the available options for the use of life-sustaining supports as follows:

1. Full support.

2. Do not intubate (DNI) or DNR status.

3. Withholding of life support.

4. Withdrawal of life support.

5. Palliative care.

\section{Definitions}

Full support: the provision of all measures needed to support hemodynamics, metabolism, and ventilation; Full resuscitation (CPR): aggressive ICU management up to and including resuscitative attempts, in the event that cardio respiratory arrest occurs; DNI/DNR: aggressive ICU management up to, but not including endotracheal intubation (DNI) or attempts at CPR (DNR); Withholding of life support: this is a considered decision not to institute new treatment or to escalate existing treatments for life support (including, but not limited to, intubation, inotropes, vasopressors, mechanical ventilation, dialysis, antibiotics, intravenous fluids, enteral, or parenteral 
nutrition) with the understanding that the treatment has a higher potential to cause pain and suffering than resolution of organ failure; Withdrawal of life support: the cessation and removal of an ongoing life-supporting treatment while not substituting an equivalent alternative treatment, with the understanding that the treatment in question is causing pain and suffering and serves no purpose other than delaying death. It is anticipated that the patient will die following the change in therapy because of the natural progression of underlying disease conditions.

Palliative care: it is the provision of active measures aimed at only alleviating pain and suffering, with no further attempt at resuscitation or providing organ support, when the underlying disease process is presumed to have reached a point of no return; This committee of the Indian society of critical care medicine emphasizes that 'euthanasia' and 'physician-assisted suicide' are illegal in India. Euthanasia is allowed in the Netherlands under certain strict regulations. Physician-assisted suicide (PAS) is legal only in the State of Oregon in the US. In India, requests for euthanasia have been turned down, ${ }^{112-}$ 14] and suicide and abetment to suicide are declared punishable by the Indian Penal Code. ${ }^{[10]}$

They are defined as follows:

Euthanasia: the taking of a human life by the direct intervention of another person (including doctors) ostensibly for the good of the patient or others.

Physician-assisted suicide: a medical doctor provides a patient with means to end his/her life (though not actively participating in the act itself).

In India, brain death is defined only for the purpose of the Transplantation of Human Organ Act 1994. Indian law does not define the state of brain death in contexts other than organ transplantation. In the opinion of this Committee, brain death should be regarded, as equivalent of death in all circumstances and the law should be suitably amended.

Brain death: Irreversible cessation of all functions of the brain including the brainstem. This category does not include patients who maintain brainstem function, such as individuals in a vegetative state.

\section{Recommendation 3}

The physician must discuss the implications of forgoing aggressive interventions through formal conferences with the capable patient or family, and work towards a shared decision-making process. Thus, he accepts patient's autonomy in making an informed choice of therapy, while fulfilling his/her obligation to provide beneficent care.

Rationale: Communication with the family is the key to making appropriate decisions and ensuring quality EOL care in the ICU. ${ }^{[17,23,38,41-47]}$ If the best interests of the patient and family are to be served, they should be involved in an informed decision-making process at the outset. Surrogates need to be well informed and free from incapacitating anxiety and depression to be able to function effectively as substitute decision-makers for the patients.

Early, open, and effective communication facilitates a more smooth transition from curative to palliative care, reduces the frequency of futile care and decreases the possibility of conflict and litigation between families and health care workers. ${ }^{[38,41,47]}$

The correlates of effective communication and family satisfaction include the provision of adequate time, frequent and consistent information provided by a single contact physician, preferably an intensivist, adequacy of physician and nurse staffing and availability of help from the family physician. ${ }^{[41-43]}$ Ensuring enough time for the family to ask questions and express themselves further enhances family satisfaction. ${ }^{[38]}$

Practice points: Empirical evidence from other cultures may not be applicable in India, where the impact of sociocultural influences upon family needs have not been studied. We can however integrate the general principles into ICU practice in India:

a. The discussions should be between the family and an intensivist. The presence of a nurse and a junior doctor will ensure consistency in subsequent discussions. It is desirable for the primary consultant and/ or the family physician to be present.

b. There should be multiple counseling sessions of adequate duration. The family must be given adequate time and opportunity to ask questions and to express their views and emotions. This should be done in a 
manner that ensures privacy, in a waiting room or similar area. ${ }^{[4]}$

c. The death of the patient as a possibility should be stated clearly and sensitively and medical and palliative treatment options should be discussed. The intensivist should enquire into any previously stated terminal care wishes or preferences directly or indirectly expressed by the patient. The discussions should include the relevant economic, ethical, and legal issues.

d. The family members may express feelings of guilt or remorse that should be resolved with patience. It might be useful to remind the family that death is inevitable and medical science cannot offer cure in all situations and that during the dying process the patient needs a humanistic approach rather than a purely technical one. In case the family has difficulties in accepting the possibility of death, counseling by a professional psychologist may be considered.

\section{Recommendation 4}

Pending consensus decisions or in the event of conflicts between the physician's recommendations and the family's wishes, all existing supportive interventions should continue. The physician however, is not morally obliged to institute new therapies against his/her better clinical judgment.

Rationale: The physician should not unduly influence the family in decision-making..$^{[7,23,35]}$ Though the emphasis on patient autonomy versus medical paternalism varies in different countries and societies, ${ }^{[3,5,16,23]}$ the worldwide trend is towards a shared decision model. . $^{[3,22,23]}$ This would minimize the influence of physician preferences, as well as social and religious biases on the issue of forgoing life support.

Several professional recommendations support the view that the physician may not be pressurized to apply treatments he does not find appropriate. ${ }^{[23]}$

\section{Practice points:}

a. The physician should guard against imposing his own values on end of life decisions or be in any way manipulative or coercive.

b. Decisions towards de-escalating the treatment may be taken in a stepwise manner through discussions until the picture becomes clearer to the family.

c. Conflicts may be resolved through improved communication and deferring decisions until the family is able to come to terms with the realities of the patient's condition. Second opinions or a psychologist's consultation may be sought. A social worker, a religious guru or a respected family elder could help overcome barriers to understanding.

d. The physician may not subject a patient to a particular therapy, even if the family may demand it, if it is against his professional judgment.

\section{Recommendation 5}

The discussions leading up to the decision to withhold life-sustaining therapies should be clearly documented in the case records, to ensure transparency and to avoid future misunderstandings. Such documentation should mention the persons who participated in the decisionmaking process and the treatments withheld or withdrawn.

Rationale: Documentation implies transparency, clarity, and evidence of an evolving decision-making process that indicates appropriate care on the part of the physician. This would be helpful to the physician to demonstrate his bonafide intentions in the event of litigation. It would provide security for the patient in case of malafide intentions on the part of caregivers or his own family. It would also ensure that the patient is informed of all the therapeutic choices available and that overall management plans are spelt out for him. Clear documentation is strongly recommended by European professional societies ${ }^{[23]}$ and the American Thoracic Society. ${ }^{[35]}$

Practice point: Details of the communications between the medical team and the family should be documented accurately and completely. The Committee does not regard the signature of a family representative to be a mandatory requirement. The specific modalities withheld or withdrawn should be documented.

\section{Recommendation 6}

The overall responsibility for the decision rests with the attending physician/intensivist of the patient, who must ensure that all members of the caregiver team including the medical and nursing staff agree with and fol- 
low the same approach to the care of the patient.

Rationale: The physician in charge of the patient is ultimately responsible for the decision although the process of decision-making requires full participation by the family/patient. The burden of the decision should not be put upon the family as several studies have found surrogates wanting in decision-making capabilities for the patient. ${ }^{[48-50]}$ The leadership role assumed by an intensivist with his experience and expertise generates trust and confidence in the family. ${ }^{[23]}$ Physicians/ intensivists should minimize inconsistencies between members of the treating team. ${ }^{[41]}$

Practice point: Medical decisions and prescriptions should be made by the primary physician/intensivist. This should take into consideration and integrate the opinions of the various sub-specialists involved in the patient's care. The primary physician/intensivist should ensure communication and uniformity between the various members of the healthcare team.

\section{Recommendation 7}

If the capable patient or family consistently desires that life support be withdrawn, in situations in which the physician considers aggressive treatment nonbeneficial, the treating team is ethically bound to consider withdrawal within the limits of existing laws.

Rationale: The physician's obligation to respect a patient's autonomy and to act in the patient's best interests does not permit him to continue a futile treatment even though the legal position is unclear. In the absence of case law, the physician may be apprehensive of the potential for litigation in the future. Obtaining signed consent for withdrawal of support may be viewed as protective to the physician but as coercive to the family. The process of withdrawal must find a suitable balance between the two concerns.

Practice points: Since Indian Law has no clear stand on EOL issues except for declaring euthanasia as a punishable offence, ${ }^{[10]}$ withdrawal even with the expressed consent of the patient or next of kin can be misinterpreted post hoc.

a. The physician must ensure clear documentation of the detailed discussions with members of the family who should be specified. The concerned physician and, ideally, the family member may sign the records, ensuring that the latter is not under pressure to comply.

b. Terminal care may be offered in the ICU, or in another area of the hospital in keeping with the wishes of the family. If the patient is discharged from the hospital preterminally, an appropriate discharge process ('discharged on request', 'left against medical advice' or 'discharged against medical advice'), in keeping with the hospital policy, should be followed.

\section{Recommendation 8}

In the event of withdrawal or withholding of support, it is the physician's obligation to provide compassionate and effective palliative care to the patient as well as attend to the emotional needs of the family.

Rationale: The US Supreme Court implicitly endorses the practice of using analgesics and sedatives to ensure that no patient dies in pain or distress. ${ }^{[38]}$ However, in high doses side effects may take place that may hasten the dying process. PAS needs to be distinguished from these as hastening of death is unintended, the primary goal of therapy being only alleviation of pain, dyspnea, or distress. Quill and associates termed it 'the double effect' to distinguish the intended and unforeseen effects. ${ }^{[51]}$ Since the Court cannot recognize intentions, we should take care to document the use of opiates and the indication for their use. ${ }^{[15]}$ This reduces the likelihood of misinterpretation or abuse. ${ }^{[15,38]}$

Practice points: When patient undergoes withdrawal/ withholding of life-sustaining modalities, the physician is ethically obliged to continue to provide care that would alleviate the patient's distress:

a. All ethical issues relating to withdrawal should be discussed thoroughly with the family. They should be assured that the patient is not being abandoned; only the treatment approach would change from 'cure' to 'care.'

b. If the patient is conscious and compos mentis, he should be clearly and with sensitivity explained what is expected to happen when a support is withdrawn. $\mathrm{He}$ should be reassured that possible pain or distress will be prevented by medication and prompt action should be taken for symptom relief.

c. The optimal dose of opiates is determined by increasing the dose until the patient's comfort is ensured. 
There is no maximum dose recommended. ${ }^{[17]}$

d. The physician should continue to be available to the family for guidance and discussion.

e. For patients discharged home for terminal care, suitable arrangements for transport and home care should be made.

f. The patient's family should be allowed free access to the patient during the last days of his life. ${ }^{[42,43]}$ The family should be encouraged to participate in the general care and nursing of the patient. ${ }^{[38]}$ Music, books, television, etc., that can help alter the environment should be made available. The patient should be allowed every opportunity to experience spiritual meaning and fulfillment. Performance of nonobtrusive bedside religious services or rites may be encouraged.

\section{Medical futility and unilateral decisions by physi- cians}

There are situations when the patient's family may insist on continuing life-support despite hopeless prognosis. The physician may have to act against his better judgment and thus face loss of self-esteem and profes- sional integrity. Even in cases of documented brain death, there have been occasions when supports have had to be continued due to the surrogates' unreasonable stand that everything possible should be done. We are obliged to define these situations and seek legal instruments to implement unilateral withdrawal of support.

\section{What constitutes medical futility?}

Here we are referring to clinical situations where, in the absence of brain death, the physician believes that continuing life support is futile and it may be justifiable to take a unilateral decision to limit life-supporting interventions for the patient. Clear and unequivocal situations of medical futility are rare. Futility may be 'quantitative' (how low are the odds of success) or 'qualitative' (what are the desired ends). ${ }^{[52]}$ Though there is no consensus even among physicians about the exact definition of futility, most conflicts between physicians and families arise from a misunderstanding of prognosis and not from discordance in the interpretation of futile care. There may be perceptions of a family pursuing 'unrealistic' or 'unwarranted' goals or a physician seeking to 'impose' his ideas on the family, which more often than

Pathway to end-of-life decision-making

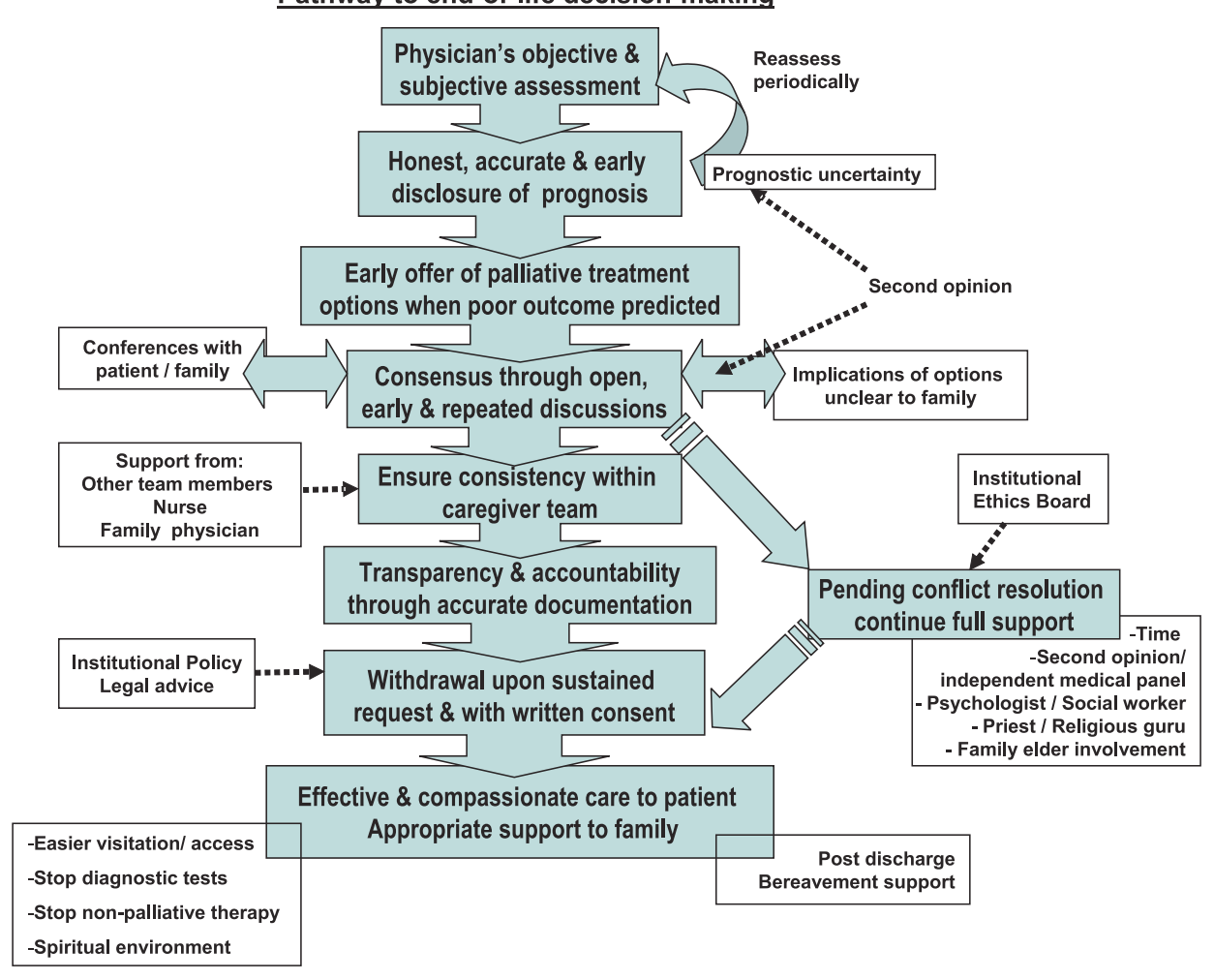


not, can be resolved by discussion. ${ }^{[35]}$

Examples of situations where the physician may consider unilateral action are: patients having a prognosis of imminent death; patients having metastatic cancers when treatment has failed or has been declined; the very elderly with dementia; patients in chronic vegetative state with organ dysfunction.

The proposed course of action may be:

1. Seeking a second opinion from another physician not hitherto involved in the care of the patient.

2. Multiple counseling sessions with the family explicitly informing the family the hopeless prognosis of the patient and the futility of continuing life support.

3. With the help of the hospital administration, setting up a committee of doctors to counsel the family. The committee may take the help of a social worker, psychologist or priest to help overcome barriers to understanding.

4. If the family remains inflexible, then suggesting transfer to another treating team that is willing to continue support.

Seeking a judicial review of medical cases for WOLS decisions has no precedence in India. Therefore, from the legal perspective unilateral action is not available to the Indian physician at present.

\section{Conclusions}

Setting goals appropriate to clinical situations of poor prognosis are an integral part of critical care. Quality critical care requires that the practice be well grounded in ethical principles and that the ICU staff is trained in the skills of end of life care. A consensus regarding the practices relating to EOL care in Indian ICUs should eventually lead to the evolution of appropriate legislation in keeping with the changing needs of critical care practice.

Position Statement approved by the ISCCM Executive Committee; Mumbai, May 7, 2005.

\section{Disclaimer}

This is the executive summary of the recommendations developed by the ISCCM Committee and represents the ethical position of the Indian Society of Critical Care Medicine. The recommendations are designed to provide a path to ethical decision-making. This docu- ment is not intended to provide legal advice on related issues in individual cases where physicians should seek appropriate legal guidance.

\section{Acknowledgments}

We are indebted to the following international experts for their invaluable suggestions on the manuscript: JeanLouis Vincent, David Crippen, Malcolm Fischer, and Leslie Whetstine.

\section{References}

1. Bone RC. You and I are dying. In: Reflections; a guide to end of life issues for you and your family. National Kidney Cancer Association: Evanston IL; 1997. p. 4-7.

2. Angus DC, Barnato AE, Linde-Zwirble WT, Weissfeld LA, Watson $\mathrm{RS}$, Rickert T, et al. Use of intensive care at the end of life in the United States: an epidemiologic study. Crit Care Med 2004;32:638-43.

3. In: Crippen D, Kilcullen JK, Kelly DF, editors. Three patients: international perspectives on intensive care at the end of life. Kluver Academic Publishers, Mass: USA; 2002.

4. Pendergast TJ, Claessens MT, Luce JM. A National Survey of End-of-life Care for critically ill patients. AJRCCM 1998;158:1163 7.

5. Ferrand E, Robert R, Ingrand P, Lemaire F, French LA. TAEREA Group. Withholding and withdrawal of life support in intensive care units in France: a prospective study. Lancet 2001;357:9 14.

6. Sprung CL, Cohen SL, Sjokvist P, Baras M, Bulow HH, Hovilehto $\mathrm{S}$, et al. End-of-life practices in European intensive care units: the ETHICUS study. JAMA 2003;290:790-7.

7. Smedira NG, Evans BH, Grais LS, Cohen NH, Lo B, Cooke M, et al. Withholding and withdrawal of life support from the critically ill. N Engl J Med 1990;322:309-15.

8. Pendergast TJ, Luce JM. Increasing incidence of withholding and withdrawal of life support from the critically ill. Am J Resp Crit Care Med 1997;155:15-20.

9. Garros D, Rosychuk RJ, Cox PN. Circumstances surrounding end-of-life care in pediatric intensive care units. Pediatrics 2003:112:e371-9.

10. Mani RK. Limitation of life support in the ICU: ethical issues relating to end-of-life care. Indian J Crit Care Med 2003;7:112-7.

11. Kapadia F, Singh M, Divatia JV, Vaidyanathan P, Udwadia FE, Raisinghaney SJ, et al. Limitation and withdrawal of intensive therapy at the end of life: Practices in intensive care units in Mumbai, India. Crit Care Med 2005;33:1272-5.

12. Sengupta A. Stay the hand, yet: Euthanasia and abuse of freedom. The Statesman 26.11.2001. 
13. Press Report: Contempt for court, own life. Hindustan Times 24-2004.

14. Press report: Terminally ill boy's last plea: let me die. The Times of India 11-12-2004.

15. Luce JM, Alpers A. Legal aspects of withholding and withdrawing life support from critically ill patients in the United States and providing palliative care to them. AJRCCM 2000;162:2029-32.

16. Luce JM, Lemaire F. Two transatlantic viewpoints on an ethical quandary. AJRCCM 2001;163:818-21.

17. Emanuel JE, Emanuel LL. Palliative and end of life care. In: Kasper DL, Fauci AS, Longo DL, Braunwald E, Hauser SL, Janson JL, editors. Harrison's Principles of Internal Medicine. $16^{\text {th }}$ edn. McGraw-Hill Co; 2005. p. 53-66.

18. Editorial. The final freedom. Venkatesh's case highlights the right to die. The Times of India 18-12-2004.

19. Minelli LA. Guest column: 'Suicide is a guaranteed right'. Hindustan Times 19-12-2004.

20. Dalmia A. Euthanasia or it's my life. The Pioneer 29-12-2004

21. American Academy Of Physician Assistants (policy adopted by AAPA). End of life decision making. 2004.http://www.aapa.org/ gandp/eol.html

22. Levy MM. Shared decision-making in the ICU: Entering a new era. Crit Care Med 2004;32:1966-8.

23. Carlet J, Thijs LG, Antonelli M, Cassell J, Cox P, Hill N, et al. Challenges in end-of-life care in the ICU: Statement of the $5^{\text {th }}$ International Consensus Conference in Critical Care: Brussels, Belgium, April 2003. Intensive Care Medicine 2004;30:770-84.

24. Christakis NA, Asch DA. Physician characteristics associated with decisions to withdraw life support. AJPH 1995;85:367-72.

25. Marik PE, Varon J, Lisbon A, Reich HS. Physicians' own preferences to the limitation and withdrawal of life-sustaining therapy. Resuscitation 1999:42:197-201.

26. Levin PD, Sprung CL. Cultural differences at the end of life. Crit Care Med 2003;31:S354-7.

27. Rocker G, Cook D, Sjokvist P, Weaver B, Finfer S, McDonald E, et al. Clinician predictions of intensive care unit mortality. Crit Care Med 2004;32:1149-54.

28. Keenan SP, Busche KD, Chen LM, McCarthy L, Inman KJ, Sibbald WJ. A retrospective review of a large cohort of patients undergoing the process of withholding or withdrawal of life support. Crit Care Med 1997;25:1324-31.

29. Luce JM. Making decisions about the forgoing of life-sustaining therapy. AJRCCM 1997;156:1715-8.

30. Marcin JP, Pollack MM, Patel KM, Ruttimann UE. Combining physician's subjective and physiology based objective mortality risk predictions. Crit Care Med 2000;28:2984-90.

31. Sinuff T, Cook DJ, Rocker GM, Griffith LE, Walter SD, Fisher $\mathrm{MM}$, et al. for the level of care study investigators \& the Cana- dian Critical Care Trials group. DNR directives are established early in mechanically ventilated intensive care patients. Can J Anaesth 2004;51:1034-41.

32. Cook D, Rocker G, Marshall J, Sjokvist P, Dodek P, Griffith L, et al. for the level of care study investigators and the Canadian Critical Care Trials group. Withdrawal of mechanical ventilation in anticipation of death in the intensive care unit. N Engl J Med 2003;349:1123-32.

33. Le Conte P, Baron D, Trewick D, Touze MD, Longo C, Vial I, et al. Witholding and withdrawing life support therapy in an emergency department: prospective survey. Intensive Care Medicine 2004;30:2216-21.

34. Hall RL, Rocker GM, Murray D. Simple changes can improve conduct of end-of-life care in the intensive care unit. Can J Anesth 2004;51:631-6.

35. American Thoracic Society. Withholding and withdrawing lifesustaining therapy. Ann Intern Med 1991;115:478-85.

36. Goh AY, Lumm LC, Chan PW, Bakar F, Chong BO. Withdrawal of life support in Pediatric intensive care. Arch Dis Child 1999;80:424-8

37. Royal College of Pediatrics and Child Health. Withholding or withdrawing life saving treatment in children. A framework for practice. London: RCPCH, 1997.

38. Troug RD, Cist FM, Brackett SE, Burns JP, Curley MA, Danis M, et al. Recommendations for end-of-life care in the intensive care unit: the ethics Committee of the Society of Critical Care Medicine. Crit Care Med 2001;29:2332-48.

39. Emanuel EJ, Emanuel L. Four models of physician-patient relationship. JAMA 1992;267:2221-26.

40. Gian Kaur Vs State of Punjab. AIR, Supreme Court 1996;83:1257-65.

41. Azoulay E, Pochard F, Chevret S, Lemaire F, Mokhtari M, Le Gall JR, et al. Meeting the needs of Intensive Care Unit patient families. AJRCCM 2001;163:135-9.

42. Molter NC. Needs of relatives of critically ill patients. Heart Lung 1979;8:332-9

43. Johnson D, Wilson M, Cavanaugh B, Bryden C, Gudmundson $\mathrm{D}$, Moodley $\mathrm{O}$. Measuring the ability to meet family needs in an intensive care unit. Crit Care Med 1998;26:266-71.

44. Hickey M. What are the needs of families of critically ill patients? A review of the literature since 1976. Heart Lung 1990;19:40115

45. Foss KR, Tenholder MF. Expectations and needs of persons with family members in an ICU as opposed to a general ward. South Med J 1993;86:380-4.

46. Price DM, Forrester DA, Murphy PA, Monaghan JF. Critical Care family needs in an urban teaching medical center. Heart Lung $1991 ; 20: 183-8$. 
47. Azoulay E, Sprung C. Family-physician interactions in the intensive care unit. Crit Care Med 2004;32:2323-8.

48. Seckler AB, Meiner DE, Mulvihill M, Paris BE. Substituted judgment: how accurate are proxy predictions? Ann Intern Med 1991;115:92-8.

49. Pochard F, Azoulay E, Chevret S, Lemaire F, Hubert P, Canoui $\mathrm{P}$, et al. Symptoms of anxiety and depression in family members of intensive care unit patients: ethical hypothesis regarding decision-making capacity. Crit Care Med 2001;29:1893-7.
50. Azoulay E, Pochard F, Chevret S, Adrie C, Annane D, Bleichner $G$, et al. Half the family members of intensive care unit do not want to share in decision-making process: A study in 78 French intensive care units. Crit Care Med 2004;32:1832-8.

51. Quill TE, Dresser R, Brock DW. The role of double effect- a critique of its role in decision-making. N Engl J Med 1997;337:176871.

52. Marco CA, Larkin G, Maskop J, Derse A. determination of futility in emergency medicine. Ann Emerg Med 2000;35:604-12. 